\title{
Overexpression of epithelial cell transforming 2 protein in colorectal carcinoma predicts a poor prognosis
}

\author{
YIMING LI $^{1,2}$, XIANGJUN CAI $^{2},{\text { BO } \mathrm{CHEN}^{1}, \mathrm{HANBO} \mathrm{GU}^{2} \text { and CAIGANG LIU }}^{1}$ \\ ${ }^{1}$ Division of Breast Surgery, Department of Surgical Oncology, General Surgery, The First Affiliated \\ Hospital of China Medical University, Shenyang, Liaoning 110001; ${ }^{2}$ Department of General Surgery, \\ 202 Hospital of People's Liberation Army, Shenyang, Liaoning 110812, P.R. China
}

Received January 24, 2016; Accepted February 17, 2017

DOI: $10.3892 / \mathrm{etm} .2017 .5132$

\begin{abstract}
Epithelial cell transforming 2 (Ect2) protein is a member of the human diffuse B-cell lymphoma family of guanine nucleotide exchange factors, which activate the Ras homolog gene family of small GTPases; however, the clinical implications of Ect2 in colorectal carcinoma (CRC) are unclear. The present study aimed to determine the relationship between Ect 2 expression and prognosis in patients with CRC. Western blot analysis and immunohistochemistry assays were used to determine the expression of Ect 2 in $\mathrm{CRC}$ and paired non-cancerous tissues from 66 patients. The correlation between Ect 2 expression and clinicopathological parameters was assessed using $\chi^{2}$ tests. Patient survival was determined using the Kaplan-Meier method and log-rank test. Cox regression was used for multivariate analysis of prognostic factors. Results demonstrated that Ect2 protein was highly expressed in human CRC samples [29/45 (64.45\%)] and significantly correlated with a poor prognosis $(\mathrm{P}<0.05)$. Compared with normal tissues, CRC tissues demonstrated higher expression levels of Ect2 mRNA [44/66 (66.67\%)]. In addition, highly-expressed Ect2 was significantly associated with recurrence $(\mathrm{P}=0.023)$ and invasion $(\mathrm{P}=0.008)$ of $\mathrm{CRC}$. High Ect2 expression levels in patients were associated with poorer overall survival (OS) and disease-free survival (DFS) compared with lower expression levels of Ect2. Based on multivariate analysis, Ect2 overexpression was significantly correlated with OS and DFS $(\mathrm{P}=0.015$ and 0.020 , respectively). In conclusion, Ect2 overexpression is an independent and important prognostic factor for OS and DFS in patients with CRC.
\end{abstract}

Correspondence to: Professor Bo Chen, Division of Breast Surgery, Department of Surgical Oncology, General Surgery, The First Affiliated Hospital of China Medical University, 155 Nanjing Street, Shenyang, Liaoning 110001, P.R. China

E-mail: stigland@qq.com

Key words: epithelial cell transforming 2, western blot analysis, immunohistochemistry assays, colorectal carcinoma, prognosis

\section{Introduction}

The incidence of colorectal cancer (CRC) varies worldwide, with the incidence of CRC being higher in North America, Australia, northern and western Europe compared with other regions. CRC is less prevalent in developing countries, particularly in Africa and Asia (1). Over $90 \%$ of CRC cases occur in people $\geq 50$ years of age (2). Nevertheless, CRC incidence appears to be increasing amongst the younger population and the incidence of CRC in individuals of $\leq 40$ years of age ranges from 1.6 to $23 \%(3,4)$. The lowest incidences of CRC are in Asia and countries in the Middle East, and the highest incidences of CRC are in Europe and the United States. The incidence of CRC has not been established in north Africa. Therefore, in order to improve the survival rate in patients with CRC, there is an urgent requirement to identify putative diagnostic markers, prognostic factors and treatment strategies.

Through the activation of the Ras homolog gene family member A (RhoA) by guanine nucleotide exchange factor (GEF) and epithelial cell transforming 2 (Ect2), the central spindle stimulates contractile ring formation (5). The central spindle complex is composed of a heterotetramer of mitotic kinesin-like protein 1 and MgcRacGAP/Cyk-4 $(6,7)$ and helps to form the central spindle during anaphase. Ect2 binds to Cyk-4 via N-terminal breast cancer $1 \mathrm{C}$-terminus domains, which recruits Ect2 to the central spindle (8-10). The GEF activity of Ect 2 is mediated by the conserved Dbl homology $(\mathrm{DH})$ and pleckstrin homology $(\mathrm{PH})$ domains in the C-terminus (11). The DH domain catalyzes nucleotide exchange on RhoA and the PH domain is involved in cortical localization of Ect2, although the molecular function, including phospholipid or protein interactions, is not known (11-14). In metaphase, cyclin dependent kinase 1 phosphorylation induces a conformational change in Ect2, which prevents Cyk-4 binding and inhibits GEF activity $(9,13)$. Despite the knowledge of the involvement of Ect2 in the cell cycle, the importance of the association between Ect2 expression levels and CRC tumor diagnosis, prognosis and clinical and pathologic features remains unclear.

The present study analyzed the expression levels of Ect2 in CRC and non-cancerous tissues using western blot analysis and immunohistochemistry. Furthermore, the 
relationship between Ect2 overexpression and clinicopathological features and post-resection survival was determined. The results of the present study demonstrated that Ect 2 may be used as an independent prognostic factor in patients with CRC and may also be used as a therapeutic target for CRC.

\section{Materials and methods}

Ethics statement. Written informed consent was provided by all patients enrolled in the present study. The study was approved by the Ethics Committee of the First Affiliated Hospital of China Medical University (Shenyang, China).

Patients. CRC and paired non-cancerous tissues were collected from 66 patients (38 males and 28 females) who had undergone hepatectomies for CRC at The First Affiliated Hospital of China Medical University and 202 Hospital of People's Liberation Army (both Shenyang, China) between July 2007 and July 2012. Histopathological analyses were performed independently by pathologists from both hospitals. The median age of the patients was 53 years (range, 37-81 years). The gender, age and clinicopathological features of patients, including tumor size, lymph node metastasis status, tumor differentiation, complication, number of tumors, histopathological differentiation, recurrence, invasion status and TNM staging are summarized in Table I. TNM staging was determined using the United Network of Organ Sharing-modified TNM staging system for CRC (15). Tumor differentiation was based on the World Health Organization criteria (16).

Western blot (WB) analysis. Total protein was extracted from 66 pairs of fresh tissue samples of CRC and paired non-cancerous tissues. Cells were lysed in pre-chilled RIPA lysis buffer (Pierce; Thermo Fisher Scientific, Inc., Waltham, MA, USA) containing protease inhibitor cocktail (Roche Diagnostics, Basel, Switzerland) for $30 \mathrm{~min}$. Samples were centrifuged at $15,000 \times \mathrm{g}$ for $20 \mathrm{~min}$ to obtain the supernatant. Following this, protein samples (30 $\mu \mathrm{g} / \mathrm{well})$ were separated by $10 \%$ SDS-PAGE and transferred onto a $0.45-\mathrm{mm}$ nitrocellulose membrane. Subsequently, the membrane was blocked at $25^{\circ} \mathrm{C}$ overnight with a blocking buffer ( $\left.\mathrm{pH} 7.6\right)$ containing $5 \%$ non-fat milk prior to incubation with primary rabbit anti-human Ect2 polyclonal antibody (1:300, according to the instruction of the reagent) for $2 \mathrm{~h}$ at room temperature. This antibody was synthesized in the Central Laboratory of the First Affiliated Hospital of China Medical University, with approval from the Ethics Committee of the First Affiliated Hospital of China Medical University and specifically recognizes an epitope in the $\mathrm{N}$-terminus of Ect2 (17). The membrane was washed with TBST three times, for $5 \mathrm{~min}$ each. Mouse anti-human $\beta$-actin antibody (1:200, $2 \mathrm{~h}$ at room temperature; sc-69879; Santa Cruz Biotechnology, Inc., Dallas, TX, USA) was used as an internal control. An incubation with secondary antibody (1:5,000, $1 \mathrm{~h}$ at room temperature; ZB-2305, ZSGB-Bio Company, Beijing, China) was performed immediately after the TBST washing. Again, the membrane was washed with TBST three times, for $5 \mathrm{~min}$ each. Immunoreactive proteins were stained using a chemiluminescence detection system
(Immunodetection System, T1046; Pierce; Thermo Fisher Scientific, Inc.).

Semi-quantitative assessment and scoring. Ect2-expressing samples were scored semi-quantitatively based on the number of positively stained cells and the staining intensity. Samples were considered positive for Ect 2 if the nucleus or cytoplasm of the sample cells had positive staining. The percent positivity (positively stained cells out of total cells in the microscopic visual field) was defined as 0 if $0 \%, 1$ if $1-10 \%, 2$ if $11-50 \%, 3$ if $51-80$ and 4 if $>80 \%$ of cells were stained. The staining intensity was scored as 3 (markedly stained), 2 (moderately stained), 1 (weakly stained) or 0 (no staining). Staining percentage and intensity were assessed by two examiners in a double-blind manner. The Ect 2 expression status (scored from $0-12$, by calculation of positivity percentage multiplied by staining intensity score) was determined from the combined results of the percentage positivity and staining intensity scores, as follows: A score of 0 was considered a negative sample; a score of 1-4 was considered to indicate low expression (1+); a score of 5-8 was considered to indicate moderate expression (2+); and a score of 9-12 was considered to indicate strong expression (3+) (18). The immunohistochemical results of Ect 2 were divided into two groups (low expression, 0-1; high expression, 2+).

RNA extraction and reverse transcription-quantitative polymerase chain reaction ( $R T-q P C R)$. Total RNA was extracted from frozen CRC and paired non-cancerous tissue samples with TRIzol reagent (Invitrogen; Thermo Fisher Scientific, Inc.). Reverse transcription (cat. no. RR037A, PrimeScript RT reagent kit, Takara Biotechnology, Co., Ltd., Dalian, China) was performed using $500 \mu \mathrm{g}$ total RNA from each sample. qPCR was performed using a SYBR Green PCR master mix (Applied Biosystems; Thermo Fisher Scientific, Inc.) and a Rotor Gene 6000 Real-Time PCR system (Applied Biosystems; Thermo Fisher Scientific, Inc.). The qPCR cycling conditions were as follows: $30 \mathrm{sec}$ at $95^{\circ} \mathrm{C}$; followed by two-step PCR for 40 cycles of $95^{\circ} \mathrm{C}$ for $5 \mathrm{sec}$, $60^{\circ} \mathrm{C}$ for $60 \mathrm{sec}$ and $85^{\circ} \mathrm{C}$ for $5 \mathrm{sec}$. Each reaction mixture contained $2 \mu \mathrm{l}$ cDNA sample, $1 \mu \mathrm{l}$ of each of the forward and reverse primers (Applied Biosystems; Thermo Fisher Scientific, Inc.), 8.5 $\mu \mathrm{l}$ RNase-free $\mathrm{H}_{2} \mathrm{O}$ and 12.5 $\mu \mathrm{l} \mathrm{SYBR}$ Green, amounting to a total reaction volume of $25 \mu 1$. $\beta$-actin was used as a reference for gene normalization. The sequences of the primers used were as follows: Ect 2 forward, 5'-TCCTCCGGGTGGACCAGAG-3', Ect2 reverse, 5'-CTG GCTTCATAATTGGAGTGC-3'; and $\beta$-actin forward, 5'-ATAGCACAGCCTGGATAGCAACGTAC-3', $\beta$-actin reverse, 5'-CACCTTCTACAATGAGCTGCGTGTG-3'. The relative levels of gene expression were determined using the $2^{-\Delta \Delta \mathrm{Cq}}$ method (19). Experiments were repeated three times.

Immunohistochemistry (IHC). Ect2 expression was examined using immunohistochemistry on paraffin-embedded samples from 66 patients with CRC. Tumor samples were fixed in $10 \%$ formalin prior to embedding the samples in paraffin. Following this, the embedded samples were cut into $5-\mu \mathrm{m}$ consecutive sections. After general deparaffinization, 
antigen retrieval was implemented with an autoclave using $0.01 \mathrm{~mol} / 1$ sodium citrate buffer $(\mathrm{pH} 6.0)$ for 30 sec. $\mathrm{H}_{2} \mathrm{O}_{2}$, $(0.3 \%)$ was added to samples to block endogenous peroxidase activity for $30 \mathrm{~min}$ at $37^{\circ} \mathrm{C}$. Non-specific immunoglobulin binding sites were blocked by incubating the samples with normal goat serum (ZSGB-Bio Company) for $30 \mathrm{~min}$ at $37^{\circ} \mathrm{C}$. Following this, sections were incubated at $4^{\circ} \mathrm{C}$ overnight with a purified primary Ect2 rabbit polyclonal antibody (1:150; NB100-74663; Novus Biologicals, LLC, Littleton, CO, USA). After three 5-min washes with phosphate buffered saline, a secondary biotinylated anti-rabbit immunoglobulin G (IgG) (NC-100, 1:300) or anti-mouse IgG antibody (NC-1390, 1:400) (both Fuzhou MaiXin Biotech Co., Ltd., Fuzhou, China) was applied to the sections for $30 \mathrm{~min}$ at room temperature. After washing with PBS three times for 5 min each, streptavidin-biotin conjugated with horseradish peroxidase (Reagent C of SP-9000, ZSGB-Bio Company) was applied to the sections for $30 \mathrm{~min}$ at room temperature, and the slides were colored with 3,3'-diaminobenzidine tetrahydrochloride. The sections were then stained with Meyer's hematoxylin. Normal rabbit/mouse IgG was used as the primary antibody at the same dilution as a negative control.

Follow-up. A total of 66 patients were available for follow-up, with follow-up time ranging from 3-53 months (median, 26 months) after experiment initiation. On 31st May 2012 (the census date), $45(68.18 \%)$ patients were alive and 21 $(38.12 \%)$ patients had succumbed to their disease.

Statistical analysis. SPSS v.17.0 software (SPSS, Inc., Chicago, IL, USA) was used for all statistical analyses. The relationships between tumor markers and other parameters were evaluated using t test and a $\chi^{2}$ test. Patient survival was analyzed using the Kaplan-Meier method and the log-rank test was used to analyze survival differences. A Cox regression model was used for univariate and multivariate analysis of prognostic parameters. $\mathrm{P}<0.05$ was considered to indicate a statistically significant difference.

\section{Results}

Expression levels of Ect $2 \mathrm{mRNA}$ in clinical tissue specimens. Ect 2 mRNA expression levels in clinical samples were determined using RT-qPCR. Of the 66 patients, $44(66.67 \%)$ demonstrated a higher level of Ect 2 mRNA in CRC tissue than in the paired non-cancerous tissue (Fig. 1). The mean level of Ect 2 mRNA expression in CRC tissues (mean \pm standard deviation, 41.75 \pm 35.10 ; standardized by $\beta$-actin gene expression) was significantly higher compared with the level $(19.21 \pm 20.03)$ in the paired non-cancerous tissues $(t=4.196$, $\mathrm{P}<0.01$; Fig. 1).

$W B$ and $I H C$. WB was used to evaluate Ect2 protein expression levels in CRC and paired non-cancerous tissues from 66 patients and expression levels were normalized to $\beta$-actin (Fig. 2). Ect 2 protein was detected by IHC in 45 CRC specimens. Overexpression of Ect 2 was observed in $\sim$ two thirds of tumor samples [29 of $45(64.45 \%) ; 2-3+]$. The remaining 16 cases $(35.55 \%$; Table I) demonstrated low levels of Ect 2 protein expression (0 to $1+$ ). Ect 2 protein expression was observed in the nucleus and cytoplasm of tumor cells at variable levels (Fig. 3). The Ect 2 staining scores were significantly influenced by recurrence and vein invasion (Table I; $\mathrm{P}=0.022$ and 0.008 , respectively); however, other clinicopathological factors did not significantly influence Ect 2 staining scores (Table I; P>0.05).

Influence of Ect2 expression levels on overall survival (OS) and disease-free survival (DFS) in CRC. According to univariate analysis, gender, tumor size, age, differentiation, histopathological type and family history were not predictive for DFS or OS (Table II; P>0.05). Invasion and TNM stage were significant predictors for DFS $(\mathrm{P}<0.001$ and $\mathrm{P}=0.009$, respectively). Ect2, TNM stage, complication and invasion were demonstrated to be significant independent prognostic factors for OS (Table II; $\mathrm{P}=0.004,0.007,0.007$ and $\mathrm{P}<0.001$, respectively). Multivariate analysis demonstrated that Ect 2 expression levels [hazard ratio $(\mathrm{HR})=1.745 ; 95 \%$ confidence interval (CI), 1.121-2.574; $\mathrm{P}=0.015]$, complication $(\mathrm{HR}=1.695 ; 95 \% \mathrm{CI}, 1.079-2.525 ; \mathrm{P}=0.019)$ and invasion $(\mathrm{HR}=2.654 ; 95 \% \mathrm{CI}, 1.452-3.378 ; \mathrm{P}<0.001)$ were significant independent prognostic factors for OS in patients with $\mathrm{CRC}$ (Table III). Furthermore, Ect 2 expression levels ( $\mathrm{HR}=1.671$; 95\% CI, 1.093-2.424; $\mathrm{P}=0.020)$, TNM stage $(\mathrm{HR}=1.633 ; 95 \%$ $\mathrm{CI}, 1.216-2.284 ; \mathrm{P}=0.038)$ and invasion $(\mathrm{HR}=2.710 ; 95 \%$ CI, 1.913-4.346; $\mathrm{P}<0.001)$ were significant independent prognostic factors for DFS in patients with CRC (Table III). According to the Kaplan-Meier method and log-rank test, CRC specimens with a higher level of Ect2 were demonstrated to have significantly shorter OS or DFS (log-rank value $=10.54$ and $8.20 ; \mathrm{P}=0.007$ and 0.003 , respectively; Fig. 4).

\section{Discussion}

Ect2, a Rho GEF, is a proto-oncogene that has transforming ability in fibroblasts and is involved in cytokinesis $(13,20)$. Ect 2 has been reported to be expressed at elevated levels in various types of cancer, including esophageal cancer, lung cancer, and glioma $(21,22)$. A study by Chalamalasetty et al (12) demonstrated that Ect2 is localized to the central spindle and the cell cortex in mitotic cells. Depletion of Ect 2 impairs cleavage furrow formation and inhibits the accumulation of RhoA and citron kinase at the cleavage furrow, suggesting that Ect2 is essential for cytokinesis (23). A study by Hirata et al (21) using tumor tissue microarray analysis indicated that a high Ect 2 expression levels are associated with poor prognosis for patients with non-small cell lung cancer. Furthermore, the study by Hirata et al (21) also demonstrated that Ect 2 knockdown by small interfering RNA was able to effectively suppress lung cancer cell growth, suggesting a specific role for Ect 2 in lung cancer development. Interestingly, Ect 2 protein expression levels were significantly upregulated in the lungs of a murine model of pulmonary squamous cancer, suggesting that increased Ect 2 expression contributes to lung tumor development (24). Thus, Ect 2 is an independent factor that may affect patient prognosis; however, it has not been determined if factors of this type are prognostic of CRC. Further studies 
Table I. Relationship between Ect2 expression levels and clinicopathological characteristics in patients with colorectal cancer.

\begin{tabular}{|c|c|c|c|c|c|}
\hline \multirow[b]{2}{*}{ Characteristic } & \multirow[b]{2}{*}{ Number } & \multicolumn{2}{|c|}{ Ect 2 expression level } & \multirow[b]{2}{*}{$\chi^{2}$} & \multirow[b]{2}{*}{ P-value } \\
\hline & & High & Low & & \\
\hline Total cases & 66 & 44 & 22 & & \\
\hline \multicolumn{6}{|l|}{ Age (years) } \\
\hline$\geq 60$ & 40 & 25 & 15 & 0.793 & 0.373 \\
\hline$<60$ & 26 & 19 & 7 & & \\
\hline \multicolumn{6}{|l|}{ Gender } \\
\hline Male & 37 & 27 & 10 & 1.507 & 0.220 \\
\hline Female & 29 & 17 & 12 & & \\
\hline \multicolumn{6}{|c|}{ Tumor size (cm) } \\
\hline$\geq 5$ & 39 & 28 & 11 & 1.128 & 0.288 \\
\hline$<5$ & 27 & 16 & 11 & & \\
\hline \multicolumn{6}{|l|}{ TNM stage } \\
\hline $\mathrm{I}+\mathrm{II}$ & 30 & 18 & 12 & 1.100 & 0.294 \\
\hline III+IV & 36 & 26 & 10 & & \\
\hline \multicolumn{6}{|c|}{ Lymph node metastasis status } \\
\hline Positive & 38 & 28 & 10 & 1.985 & 0.159 \\
\hline Negative & 28 & 16 & 12 & & \\
\hline \multicolumn{6}{|c|}{ Tumor differentiation } \\
\hline WD & 27 & 19 & 8 & 0.354 & 0.838 \\
\hline MD & 24 & 15 & 9 & & \\
\hline PD & 15 & 10 & 5 & & \\
\hline \multicolumn{6}{|l|}{ Complications } \\
\hline Yes & 35 & 20 & 15 & 3.041 & 0.081 \\
\hline No & 31 & 24 & 7 & & \\
\hline \multicolumn{6}{|c|}{ Number of tumors } \\
\hline Single & 36 & 23 & 13 & 0.275 & 0.600 \\
\hline More & 30 & 21 & 9 & & \\
\hline \multicolumn{6}{|l|}{ Recurrence } \\
\hline Yes & 37 & 29 & 8 & 5.198 & 0.023 \\
\hline No & 29 & 15 & 14 & & \\
\hline \multicolumn{6}{|l|}{ Invasion } \\
\hline Yes & 39 & 31 & 8 & 7.051 & 0.008 \\
\hline No & 27 & 13 & 14 & & \\
\hline
\end{tabular}

Ect2, epithelial cell transforming 2; WD, well-differentiated; MD, moderately differentiated; PD, poorly differentiated.

are required to determine if Ect2 may be applied to estimate the prognosis of other types of cancer.

In the present study, IHC revealed that there was a significant association between elevated Ect 2 expression levels and tumor invasion and recurrence in the $66 \mathrm{CRC}$ specimens examined according to $\chi^{2}$ tests; however, there was no significant relationship with other clinicopathological parameters of CRC, including age, gender, tumor size, TNM stage, lymph node metastasis status, tumor differentiation, complication and number of tumors. These findings therefore suggest that Ect 2 expression level is relative to CRC invasion and recurrence, and that Ect 2 may have an important role in tumor carcinogenesis and CRC progression. Furthermore, patients who overexpressed Ect2 had a lower DFS and OS following surgery than those who demonstrated reduced Ect2 expression levels, according to Kaplan-Meier analysis. Multivariate Cox regression analysis indicated that, among the variables analyzed, elevated Ect 2 expression was an independent prognostic factor for DFS and OS, without new recurrent tumors. According to the data obtained, the results indicated that high Ect2 expression levels may be associated with a poor prognosis, which also suggests that Ect 2 may be a novel independent prognostic indicator in patients with CRC. Based on the staining results, it was demonstrated that Ect 2 may be important in predicting CRC recurrence; however, the mechanism involved is unclear. A study by 
Table II. Univariate survival analyses of individual parameters for correlations with DFS and OS.

\begin{tabular}{|c|c|c|c|c|c|c|}
\hline \multirow[b]{2}{*}{ Variable } & \multicolumn{3}{|c|}{ OS } & \multicolumn{3}{|c|}{ DFS } \\
\hline & HR & CI $(95 \%)$ & P-value & HR & CI $(95 \%)$ & P-value \\
\hline Ect2 & 1.823 & $1.192-2.633$ & $0.004^{\mathrm{a}}$ & 1.654 & $1.085-2.374$ & $0.008^{\mathrm{a}}$ \\
\hline Age (years) & 1.142 & $0.754-1.571$ & 0.875 & 1.021 & $0.700-1.424$ & 0.912 \\
\hline Gender & 1.241 & $0.734-1.762$ & 0.524 & 1.101 & $0.699-1.754$ & 0.722 \\
\hline Tumor size & 1.331 & $0.899-1.995$ & 0.201 & 1.241 & $0.810-1.891$ & 0.207 \\
\hline TNM stage & 1.754 & $1.275-2.531$ & $0.007^{\mathrm{a}}$ & 1.568 & $1.012-2.372$ & $0.009^{\mathrm{a}}$ \\
\hline Histopathologic differentiation & 0.935 & $0.704-1.206$ & 0.701 & 0.896 & $0.712-1.304$ & 1.002 \\
\hline Family history & 1.254 & $0.703-1.507$ & 0.824 & 1.145 & $0.785-1.593$ & 0.513 \\
\hline Complication & 1.721 & $1.135-2.643$ & $0.007^{\mathrm{a}}$ & 1.401 & $0.937-2.081$ & 0.097 \\
\hline Invasion & 2.456 & $1.654-3.681$ & $<0.001^{\mathrm{a}}$ & 3.245 & $2.112-4.897$ & $<0.001^{\mathrm{a}}$ \\
\hline
\end{tabular}

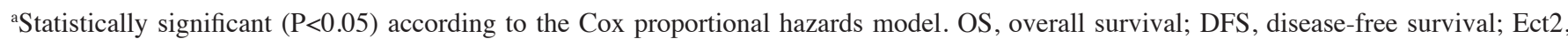
epithelial cell transforming 2; HR, hazard ratio; CI, confidence interval.
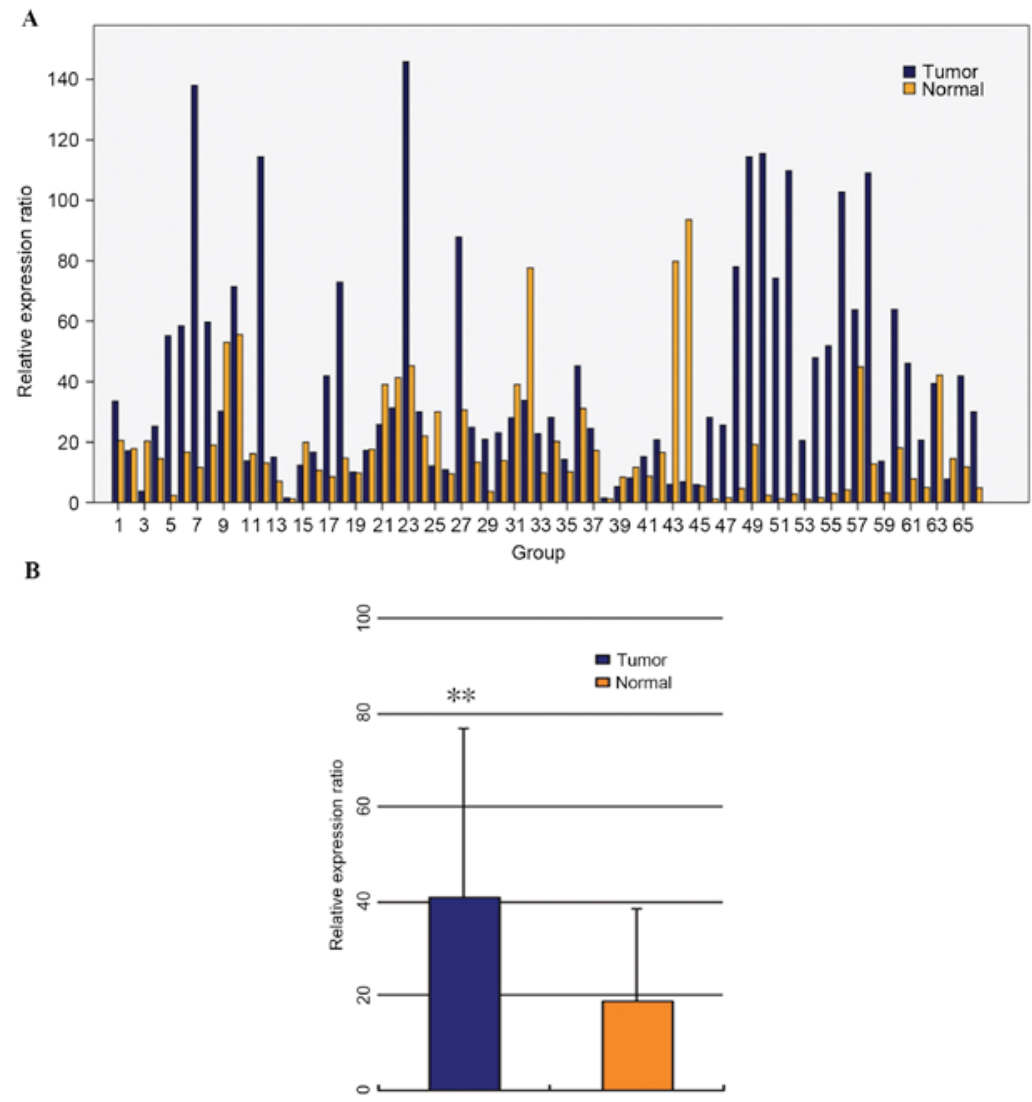

Figure 1. Reverse transcription-quantitative polymerase chain reaction analyses of Ect2 mRNA expression levels in (A) 66 CRC and paired non-cancerous tissues. (B) Mean Ect 2 mRNA expression level in 66 CRC and paired non-cancerous tissues. mRNA expression levels were normalized to $\beta$-actin. Data are presented as the mean + standard deviation. Tumor; CRC tissue; Normal, non-cancerous tissue; Ect2, epithelial cell transforming 2; CRC, colorectal cancer. ${ }^{* *} \mathrm{P}<0.01$ vs. normal tissue.

Hayashi et al (25) reported that recurrence of CRC in patients was associated with poor prognosis. It is possible to hypothesize that when Ect2 expression is stable, dephosphorylation of Ect 2 is inhibited, which may promote the recurrence of $\mathrm{CRC}$; however, the signal pathway in which the coding gene has been changed is unknown.
In conclusion, the present study demonstrated that Ect2 is overexpressed in a great proportion of CRC cases, and that high Ect 2 expression levels are associated with the poor results in CRC post resection. Therefore, Ect 2 may be applied as an independent biomarker to examine increased risk of recurrence. Furthermore, Ect 2 overexpression has been 
Table III. Multivariate survival analyses of individual parameters for correlations with OS and DFS.

\begin{tabular}{|c|c|c|c|c|c|c|}
\hline \multirow[b]{2}{*}{ Variables } & \multicolumn{3}{|c|}{ OS } & \multicolumn{3}{|c|}{ DFS } \\
\hline & $\mathrm{HR}$ & CI (95\%) & P-value & HR & CI (95\%) & P-value \\
\hline Ect2 & 1.745 & $1.121-2.574$ & $0.015^{\mathrm{a}}$ & 1.671 & $1.093-2.424$ & $0.020^{\mathrm{a}}$ \\
\hline TNM stage & & & & 1.633 & $1.216-2.284$ & $0.038^{\mathrm{a}}$ \\
\hline Complication & 1.695 & $1.079-2.525$ & $0.019^{\mathrm{a}}$ & & & \\
\hline Invasion & 2.654 & $1.452-3.378$ & $<0.001^{\mathrm{a}}$ & 2.710 & $1.913-4.346$ & $<0.001^{\mathrm{a}}$ \\
\hline
\end{tabular}

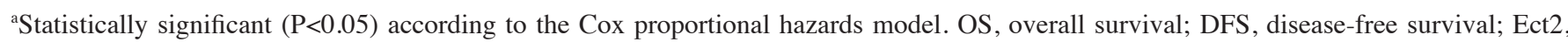
epithelial cell transforming 2; HR, hazard ratio; CI, confidence interval.

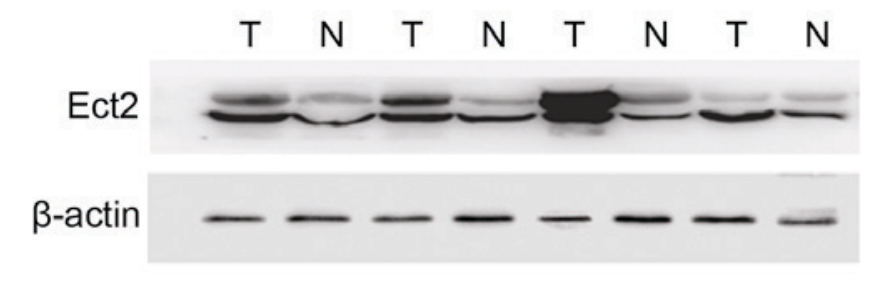

Figure 2. Expression of Ect2 protein identified by western blot analysis in $\mathrm{CRC}$ and paired non-cancerous tissues from the same patient. Levels of Ect2 expression were analyzed in tissues from 66 patients. Densitometry was normalized to $\beta$-actin. Ect2, epithelial cell transforming 2; T, CRC tissue; $\mathrm{N}$, non-cancerous tissue; $\mathrm{CRC}$, colorectal cancer.
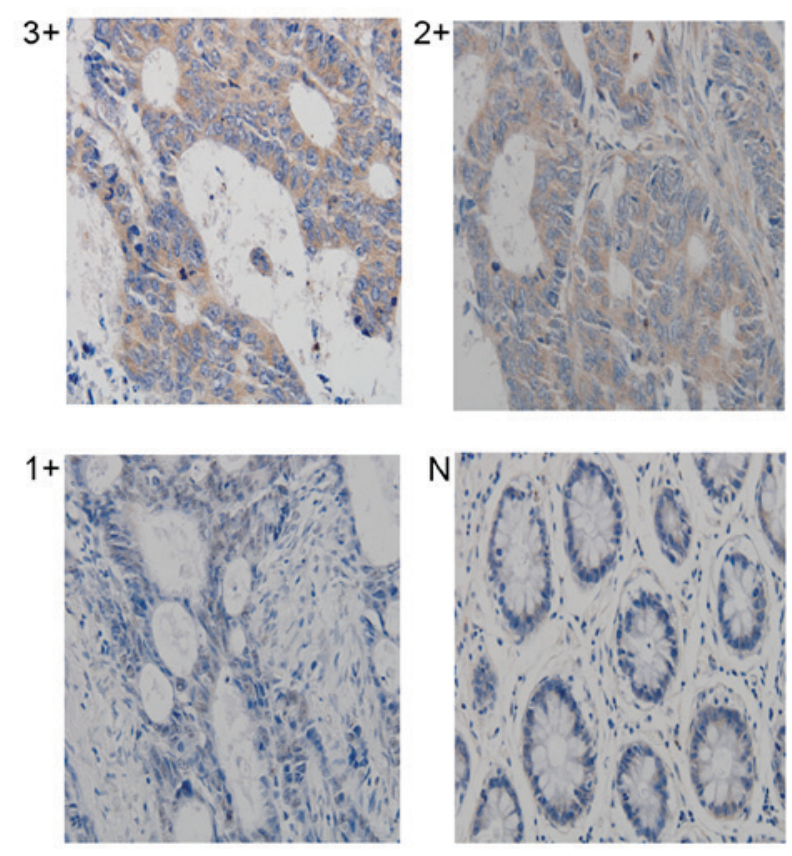

Figure 3. Immunohistochemistry (stain, hematoxylin; magnification, $\mathrm{x} 400$ ) with anti-Ect2 antibodies in CRC and paired non-cancerous tissues. Representative tissue sections with different immunochemical staining intensities ( 0 to $3+)$ of Ect 2. 3+, strong Ect2 expression in CRC; $2+$, moderate expression of Ect2 in CRC; $1+$, weak expression of Ect2 in CRC; $\mathrm{N}$, negative expression of Ect2 in CRC. Ect2, epithelial cell transforming 2; CRC, colorectal cancer.

demonstrated to be an independent prognostic indicator in CRC and Ect2 may therefore be a novel molecular biomarker

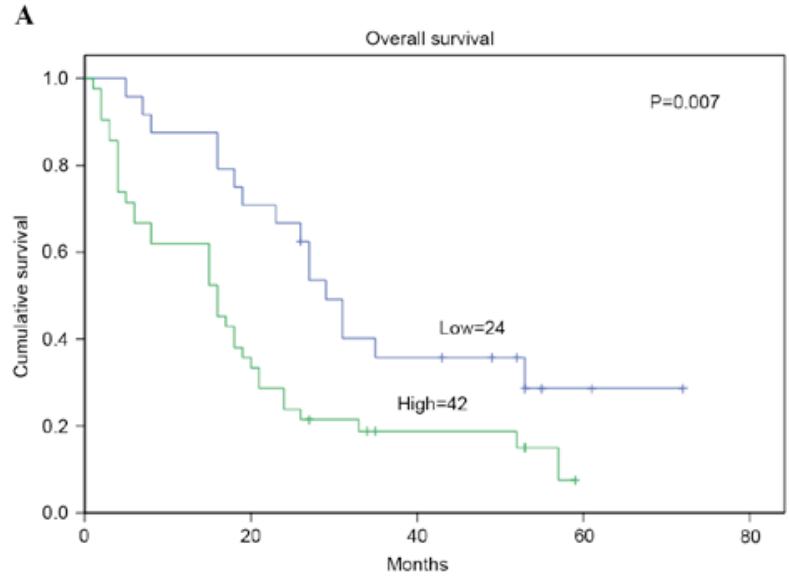

B

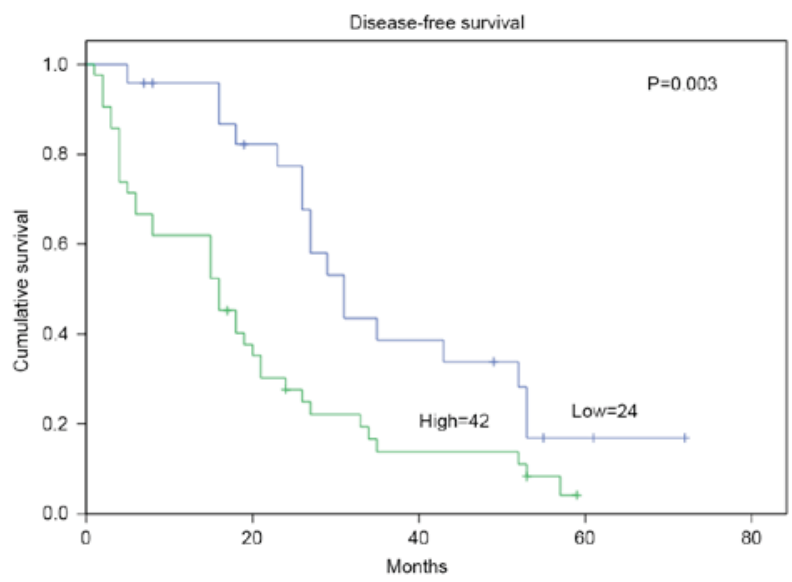

Figure 4. Kaplan-Meier survival analysis of patients with primary colorectal cancer $(n=66)$ after surgical resection with high $(n=44)$ and low $(n=22)$ epithelial cell transforming 2 expression levels. (A) Overall survival and (B) disease-free survival after hepatectomy.

in the diagnosis and prognosis, or a therapeutic target, of this deadly disease.

\section{Acknowledgments}

The present study was supported by the National Natural Science Foundation Project (grant no. 30972939) and the Doctoral Startup Fund of Science and Technology Agency, Liaoning Province (grant no. 20061038). 


\section{References}

1. Ferlay J, Parkin DM and Steliarova-Foucher E: GLOBOCAN 2008, Cancer incidence and mortality worldwide. IARC cancer base No. 10, International Agency for Research on Cancer Lyon, 2010. http://www.iarc.fr/en/media-centre/iarcnews/2010/ globocan2008.php; Accessed January 5, 2010.

2. Ries LAG, Melbert D, Krapcho M, Stinchcomb DG, Howlader N, Horner MJ, Mariotto A, Miller BA, Feuer EJ, Altekruse SF, et al (eds): SEER cancer statistics review, 1975-2005, 2008 , National Cancer Institute, Bethesda, MD, http://seer.cancer. gov/csr/1975_2005/; Accessed April 17, 2008.

3. Chung YF, Eu KW, Machin D, Ho JM, Nyam DC, Leong AF, Ho YH and Seow-Choen F: Young age is not a poor prognostic marker in colorectal cancer. Br J Surg 85: 1255-1259, 1998

4. Cusack JC, Giacco GG, Cleary K, Davidson BS, Izzo F, Skibber J, Yen J and Curley SA: Survival factors in 186 patients younger than 40 years old with colorectal adenocarcinoma. J Am Coll Surg 183: 105-112, 1996.

5. Piekny A, Werner M and Glotzer M: Cytokinesis: Welcome to the Rho zone. Trends Cell Biol 15: 651-658, 2005.

6. Mishima M, Kaitna S and Glotzer M: Central spindle assembly and cytokinesis require a kinesin-like protein/RhoGAP complex with microtubule bundling activity. Dev Cell 2: 41-54, 2002 .

7. Mishima M, Pavicic V, Grüneberg U, Nigg EA and Glotzer M: Cell cycle regulation of central spindle assembly. Nature 430: 908-913, 2004

8. Somers WG and Saint R: A RhoGEF and Rho family GTPase-activating protein complex links the contractile ring to cortical microtubules at the onset of cytokinesis. Dev Cell 4: 29-39, 2003.

9. Yuce O, Piekny A and Glotzer M: An ECT2-centralspindlin complex regulates the localization and function of RhoA. J Cell Biol 170: 571-582, 2005.

10. Zhao WM and Fang G: MgcRacGAP controls the assembly of the contractile ring and the initiation of cytokinesis. Proc Nat Acad Sci USA 102: 13158-13163, 2005.

11. Solski PA, Wilder RS, Rossman KL, Sondek J, Cox AD, Campbell SL and Der CJ: Requirement for C-terminal sequences in regulation of Ect2 guanine nucleotide exchange specificity and transformation. J Biol Chem 279: 25226-25233, 2004.

12. Chalamalasetty RB, Hümmer S, Nigg EA and Silljé HH: Influence of human Ect2 depletion and overexpression on cleavage furrow formation and abscission. J Cell Sci 119: 3008-3019, 2006.

13. Saito S, Liu XF, Kamijo K, Raziuddin R, Tatsumoto T, Okamoto I, Chen X, Lee CC, Lorenzi MV, Ohara N and Miki T: Deregulation and mislocalization of the cytokinesis regulator Ect 2 activate Rho signaling pathways leading to malignant transformation. J Biol Chem 279: 7169-7179, 2004.
14. Tatsumoto T, Xie X, Blumenthal R, Okamoto I and Miki T: Human ECT2 is an exchange factor for Rho GTPases, phosphorylated in $\mathrm{G} 2 / \mathrm{M}$ phases, and involved in cytokinesis. J Cell Biol 147: 921-928, 1999.

15. Lin J, Qiu M, Xu R and Dobs AS: Comparison of survival and clinicopathologic features in colorectal cancer among African American, Caucasian and Chinese patients treated in the United States: Results from the surveillance epidemiology and end results (SEER) database. Oncotarget; 6: 33935-33943, 2015.

16. Kim JW, Shin MK and Kim BC: Clinicopathologic impacts of poorly differentiated cluster-based grading system in colorectal carcinoma. J Korean Med Sci 30: 16-23, 2015.

17. Wolfe BA, Takaki T, Petronczki M and Glotzer M: Polo-like kinase 1 directs assembly of the HsCyk-4 RhoGAP/Ect2 RhoGEF complex to initiate cleavage furrow formation. PLoS Bio 7: e1000110, 2009.

18. Engers R, Mueller M, Walter A, Collard JG, Willers R and Gabbert HE: Prognostic relevance of Tiam1 protein expression in prostate carcinomas. Br J Cancer 95: 1081-1086, 2006.

19. Livak KJ and Schmittgen TD: Analysis of relative gene expression data using real-time quantitative PCR and the 2(-Delta Delta C(T)) method. Methods 25: 402-408, 2001.

20. Miki T, Smith CL, Long JE, Eva A and Fleming TP: Oncogene ect2 is related to regulators of small GTP-binding proteins. Nature 362: 462-465, 1993.

21. Hirata D, Yamabuki T, Miki D, Ito T, Tsuchiya E, Fujita M, Hosokawa M, Chayama K, Nakamura Y and Daigo Y: Involvement of epithelial cell transforming sequence-2 oncoantigen in lung and esophageal cancer progression. Clin Cancer Res 15: 256-266, 2009.

22. Sano M, Genkai N, Yajima N, Tsuchiya N, Homma J, Tanaka R, Miki T and Yamanaka R: Expression level of ECT2 proto-oncogene correlates with prognosis in glioma patients. Oncol Rep 16: 1093-1098, 2006.

23. Bui DA, Lee W, White AE, Harper JW, Schackmann RC, Overholtzer M, Selfors LM and Brugge JS: Cytokinesis involves a nontranscriptional function of the Hippo pathway effector YAP. Sci Signal 9: ra23, 2016.

24. Woik N, Dietz CT, Schäker K and Kroll J: Kelch-like ECT2-interacting protein KLEIP regulates late-stage pulmonary maturation via Hif- $2 \alpha$ in mice. Dis Model Mech 7: 683-692, 2014.

25. Hayashi M, Inoue Y, Komeda K, Shimizu T, Asakuma M, Hirokawa F, Miyamoto Y, Okuda J, Takeshita A, Shibayama Y and Tanigawa N: Clinicopathological analysis of recurrence patterns and prognostic factors for survival after hepatectomy for colorectal liver metastasis. BMC Surg 10: 27, 2010. 